\title{
Adaptation-level theory: Absolute or relative anchor effectiveness?
}

\section{VIKTOR SARRIS, University of Duesseldorf, Germany}

In this study, on anchor effectiveness, the hypothesis was tested that the locus of inflection-points of adaptation-level varies with relative distance of anchors from series. Altogether $178 \mathrm{Ss}$, randomly divided into $19 \mathrm{groups,} \mathrm{had} \mathrm{to} \mathrm{judge} \mathrm{either} \mathrm{a}$ $800-2000 \mathrm{~g}$ weights series or a 20-180 g series with anchor values ranging either from 10 to $970 \mathrm{~g}$ or from 120 to $4500 \mathrm{~g}$. The experimental results which are opposed to Helson's model support the writer's "relativity" concept of anchor effectiveness.

The concept of adaptation-level (AL) represents a comprehensive theory of psychological relativity; its most essential part is the "weighted log mean definition" of the AL (Helson, 1947, 1964). While this mathematical model clearly predicts the $\mathrm{AL}$ as being a monotonic function of anchor value, recent lifted weights studies demonstrated that the anchor-AL relationship follows a cubic trend; i.e., two $\mathrm{AL}$ inflection-points were experimentally established with extreme anchors relative to the series (Helson \& Masters, 1966; Sarris, 1967).

Helson and Masters explained these noteworthy discrepancies from the AL model with a rather absolute line of reasoning: The lower inflection-point was interpreted as a natural consequence of anchor values near zero, and the upper one was accounted for by changes in physiological, i.e., muscular, conditions when lifting heavy anchors (Helson \& Masters, 1966 , p. 400, p. 406). Both post hoc hypotheses imply the consequence that with variable series the two $\mathrm{AL}$ inflection-points should occur roughly at the same values when the same anchors are used.

A comparison of the findings from Helson and Masters' and the author's studies suggest that this is not the case. Helson and Masters, using a constant series of $100-300 \mathrm{~g}$, found that the two AL inflection-points occurred with anchors of about 25 and $1600 \mathrm{~g}$ while in the author's research, employing a series of $200-400 \mathrm{~g}$, the two inflection-points occurred with anchors of approximately 75 and $2900 \mathrm{~g}$. Though this shifting of inflection-points may be partly due to differences in the experimental procedures, the above findings give rise to an alternative hypothesis, namely, that the locus of $\mathrm{AL}$ inflection-points is a function of the numerical distance of anchors from the series. This assumption implies systematic shifts of inflection-points with variable series. The present study was designed to test these alternative hypotheses of "absolute" vs "relative" anchor effectiveness.

\section{Stimuli and Subjects}

\section{METHOD}

In the writer's earlier experiment, by use of a randomized-groups design, $160 \mathrm{Ss}$ had to judge a constant series of $200,250,300,350$, and $400 \mathrm{~g}$ weights under 10 different anchor conditions, the anchors measuring 12.4, 35, $75,291.4,450,900,1500,2400,3400$, and $4500 \mathrm{~g}$ (Sarris, 1967). In this study it was decided to employ approximately the same anchor values but to use two additional series, namely, a relatively heavy one, i.e., $800,1100,1400,1700$, $2000 \mathrm{~g}$, in order to test for a lower inflection-point, and a relatively light one, i.e., $20,60,100,140,180 \mathrm{~g}$, in order to test for an upper inflection-point. The above design was planned so that a comparison of the loci of $A L$ inflection-points from this experiment could be made with those already obtained in the author's previous study (Sarris, 1967).
For the heavy series the following eight anchors spaced logarithmically and being below the series midpoint were used (number of Ss given in brackets): $10(10), 20(10), 40(10), 80$ (10), $160(10), 320(6), 630(6)$, and $970(6) \mathrm{g}$. The 970-g measure served as a control since this was the empirically established AL value for the heavy series without any anchor (20 control Ss). Similarly, for the light series the following nine anchors spaced logarithmically and being above the series midpoint were used: $120(6), 200(6), 316(6), 501(6), 794$ (6), $1259(10), 1995(10), 3162(10)$, and $4500(10) \mathrm{g}$. The 120-g measure served likewise as a control since this was the empirical $A L$ value for the light series without any anchor (20 control Ss).

Summing up, 178 Ss (right-handed soldiers) randomly divided into a total of 17 experimental groups (receiving anchors) and two control groups (no anchor) had to judge either the heavy- or the light-weights series.

Apparatus and Procedure

By means of the same semi-automatic apparatus as used in the writer's earlier study (Sarris, 1967) the single weights were successively presented to S's right hand. The stimuli which consisted of plastic bottles filled with variable amounts of lead shot were concealed from S's eyes by a shield. The experimental procedure followed the writer's earlier investigation, i.e., Ss had to judge the series stimuli under the various conditions according to Helson's bipolar rating scale ranging in nine steps from "very, very light" to "very, very heavy." Again, in random permutation order, E presented first 10 practice runs and then 10 test runs to Ss (for details see Sarris, 1967).

\section{RESULTS AND DISCUSSION}

The $178 \mathrm{Ss}$ mean judgments for the 10 test runs were analyzed first by calculating the empirical ALs (Helson \& Himelstein, 1955). Then the $A L$ values for the different anchor conditions were investigated separately for the heavyand the light-weights series.

As expected from previous results (see above), both parametric (Gaito, 1965) and nonparametric (Ferguson, 1965) trend analyses demonstrated that the quadratic and bitonic components of the anchor-AL relationships were statistically significant, both for the $800-2000 \mathrm{~g}$ series $[\mathrm{F}(1,60)=26.30$; $\mathrm{z}=3.67 ; \mathrm{p}<0.001]$ and for the $20-180 \mathrm{~g}$ series $[F(1,61)=21.43 ; z=-2.59 ; p<0.01]$. This finding which

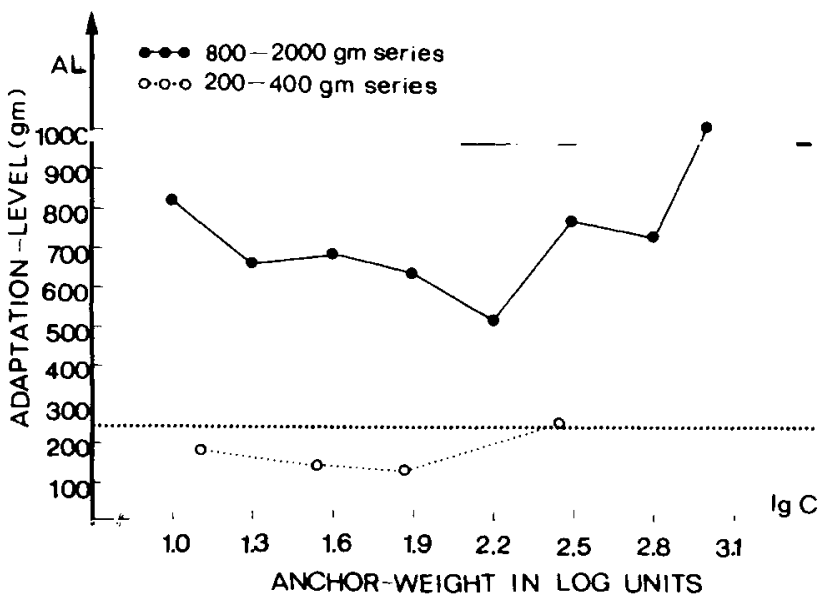

Fig. 1. Anchor-AL relationship for the $800-2000 \mathrm{~g}$ series and the $200-400 \mathrm{~g}$ comparison series. 


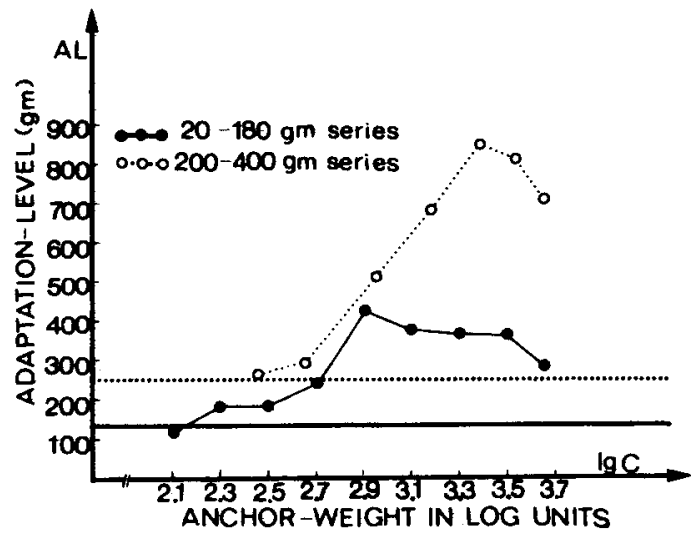

Fig. 2. Anchor-AL relationship for the $20-180 \mathrm{~g}$ series and the $200-400$ g comparison series.

again, is inconsistent with Helson's model $(1947,1964)$ is graphically represented in Fig. 1 (heavy series) and Fig. 2 (light series) which show the geometric mean $A L$ values (ordinate) against the experimental anchor values $C$ in $\log$ units (abscissa).

In this context, however, the even more important result is obtained by means of curve fitting and respective graphical interpolation for each anchor-AL trend: For the heavy series $(800-2000 \mathrm{~g})$ with light anchors an inflection-point occurs at an anchor of about $125 \mathrm{~g}(\log \mathrm{C} \doteq 2.1)$ as contrasted to the inflection-point of about $75 \mathrm{~g}(\log \mathrm{C} \doteq 1.9)$ for the $200-400 \mathrm{~g}$ series (see Fig. 1). The light series (20-180 g) with heavy anchors yielded an inflection-point at an anchor of about $1100 \mathrm{~g}(\log \mathrm{C} \doteq 3.05)$ as contrasted to the inflection-point of about $2900 \mathrm{~g} \quad(\log \mathrm{C}=3.45$ ) for the $200-400 \mathrm{~g}$ series (see Fig. 2).

The shifting of inflection-points with different series is contrary to Helson and Masters' explanation but it well supports the writer's prediction since it appears from the data shown in Figs. 1 and 2 that the locus of $A L$ inflection-points is dependent not on the absolute anchor values, but on the relative distance of anchors from series. This crucial finding is, moreover, consistent with the results of recent experiments on pitch judgments insofar as systematic variation of both anchor and series also yielded a corresponding trend of shifts in AL inflection-points (Sarris, in press).

It is supposed that the relative anchor effectiveness may be best explained by the so-called "class hypothesis" in that "...very extreme anchors relative to the series-stimuli are implicitly experienced as not yet belonging to the possible stimulus-series 'class' which is to be judged by Ss" (Sarris, 1967, p. 342). This assumption implies less weighing of more extreme anchors relative to the series.

Though the main conclusion from this study is opposed to Helson's AL model, it may be well interpreted in the light of general AL theory since in its essence Helson's concept is a theory of "relativity." In fact, the above interpretation might be regarded most adequately as a prolific supplement of $A L$ theory's basic concern. However, it is also assumed here that Helson's mathematical model must be revised according to the experimental evidence. A first approach to this very delicate problem has been tentatively made elsewhere (Sarris, 1967).

\section{REFERENCES}

FERGUSON, G. A. Nonparametric trend analysis. Montreal: McGill University Press, 1965.

GAITO, J. Unequal intervals and unequal $n$ in trend analysis. Psychological Bulletin, 1965, 63, 125-127.

HELSON, $H$. Adaptation-level as frame of reference for prediction of psy chophysical data. American Journal of Psychology, 1947, 60, 1-29. HELSON, H. Adaptation-level theory. New York: Harper \& Row, 1964.

HELSON, H., \& HIMELSTEIN, P. A short method for calculating the adaptation-level for absolute and comparison rating judgments. American Journal of Psychology, 1955, 68, 631-637.

HELSON, H., \& MASTERS, H. G. A study of inflection-points in the locus of adaptation-levels as a function of anchor-stimuli. American Joumal of Psychology, 1966, 79, 400-408.

SARRIS, V. Adaptation-level theory: Two critical experiments on Helson's weighted-average model. American Journal of Psychology, $1967,80,331-344$

SARRIS, V. Ankerreiz-Effekte bei Tonhöhenbeurteilungen: Überprüfung von Helsons Adaptationsniveau-Modell. In M. Irle (Ed.), Bericht vom 26. Kongress der DGfP in Tübingen. In press. NOTE

1. Research supported by a grant of the "Deutsche Forschungsgemeinschaft," Bad Godesberg, Germany. The author wishes to thank Dr. Joe A. Steger, State University of New York at Albany, for help in reading the manuscript. 